\title{
Posttraumatic Carotid Cavernous Fistula-A Rare Case
}

\author{
Amit Dahiya $\quad$ Sumit Dahiya ${ }^{1} \quad$ Suresh Kumar S ${ }^{1} \quad$ Shrikant V Rege ${ }^{1} \quad$ Gaurav Jatav ${ }^{1}$ \\ Krishna Chaitanya ${ }^{1}$ Sandeep Varma ${ }^{1}$
}

${ }^{1}$ Department of Neurosurgery, Sri Aurobindo Institute of Medical

Address for correspondence Amit Dahiya, MCh, Department of

Sciences, Indore, India

Neurosurgery, Sri Aurobindo Institute of Medical Sciences, Doctors Quarters

Flat No-8, Indore 453555, India (e-mail: doc.amitdahiya@gmail.com).

Indian J Neurotrauma 2021;18:142-145.

\begin{abstract}
Keywords

- CCF

- head injury

- posttraumatic

pulsating proptosis

- posttraumatic carotid cavernous fistula

- proptosis

Carotid cavernous fistula (CCF) is a specific type of dural arteriovenous (AV) fistula characterized by abnormal AV shunting within the cavernous sinus. The authors presented in this article a case of a 17-year-old young male patient who encountered a road traffic accident while driving a car, with a history of flipping of cars multiple times. The patient was unconscious with symmetrical bilateral $(\mathrm{B} / \mathrm{L})$ pupils and with Glasgow coma scale (GCS) score of 3. There was no history of seizures or vomiting.
\end{abstract}

\section{Introduction}

Carotid cavernous fistula (CCF) is a specific type of dural arteriovenous (AV) fistula characterized by abnormal AV shunting within the cavernous sinus, which results in high-pressure arterial blood entering low pressure venous cavernous sinus; thus, interfering with normal venous drainage patterns and compromising blood flow within the cavernous sinus and the orbit. ${ }^{1}$ We presented a case of CCF as a sequela of closed head injury.

\section{Case Report}

A 17-year-old male patient presented to the emergency department after being referred from an outside hospital with a history of road traffic accident while driving a car and a history of flipping of cars multiple times. The patient was intubated with symmetrical bilateral $(\mathrm{B} / \mathrm{L})$ pupils and a Glasgow coma scale (GCS) score of 3. There was no history of seizures or vomiting. Initially, CT scan of the brain, performed in the emergency department, revealed left frontotemporoparietal acute SDH (subdural hematoma), right frontal bone fracture, bilateral maxillary fracture with hemosinus, and skull base fracture with bilateral nasal bone fracture (-Figs. 1-4). The patient was managed conservatively with antiepileptics, antibiotics, analgesics and dehydration therapy. Tracheostomy and open reduction internal fixation

published online September 23, 2020
DOI https://doi.org/ $10.1055 / \mathrm{s}-0040-1717218$ ISSN 2277-954X.
(ORIF) (B/L maxillary) were done. The patient was gradually taken off from ventilator, shifted to ward and discharged. The patient was kept on regular follow-up. Follow-up repeat CT was done after 6 months which showed dilated and tortuous superior ophthalmic vein (-Fig. 5).

On examination, exophthalmos was present on right side (-Fig. 6); however, the patient was not having any visual disturbance. There was no blurring of vision, conjunctival chemosis, and cranial nerve palsy. The patient was not having any headache or ocular pain, and there was no bruit on auscultation. CT angiogram was done and showed a fistulous communication between the right intracavernous internal carotid artery (ICA) (at lateral wall) and cavernous sinus (CS). Right cavernous sinus was enlarged. Right sphenoparietal sinus, superficial middle cerebral vein, and superior ophthalmic vein were enlarged and tortuous ( - Figs. 7 and 8 ).

\section{Discussion}

CCFs represent 12 percent of all dural AV fistulas. They can be direct CCFs, which are secondary to trauma with acute and rapid presentation or indirect CCFs, which are usually seen postmenopause with insidious presentation., ${ }^{2,3}$ Based on site of communication between arterial system and cavernous sinus, they can be classified as type A, B, C and D. ${ }^{3}$ Type A-Direct connection between the intracavernous ICA and CS; type BDural shunt between intracavernous ICA and CS; type C-Dural

(C) 2020. Neurotrauma Society of India.

This is an open access article published by Thieme under the terms of the Creative Commons Attribution-NonDerivative-NonCommercial-License, permitting copying and reproduction so long as the original work is given appropriate credit. Contents may not be used for commercial purposes, or adapted, remixed, transformed or built upon. (https://creativecommons.org/licenses/by-nc-nd/4.0/).

Thieme Medical and Scientific Publishers Pvt. Ltd. A-12, 2nd Floor, Sector 2, Noida-201301 UP, India 


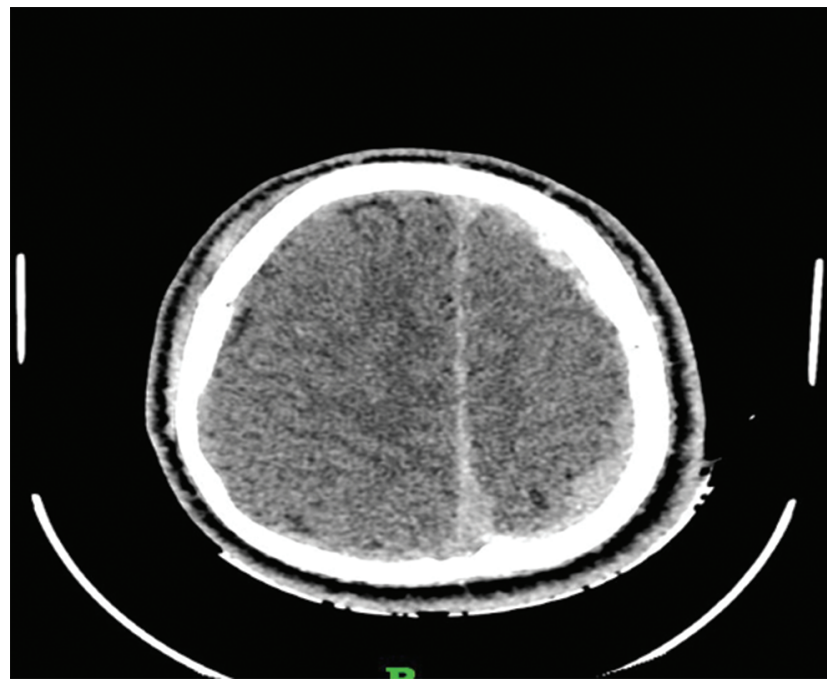

Fig. 1 Plain CT brain showing left frontotemporoparietal (FTP) acute subdural hematoma (SDH).

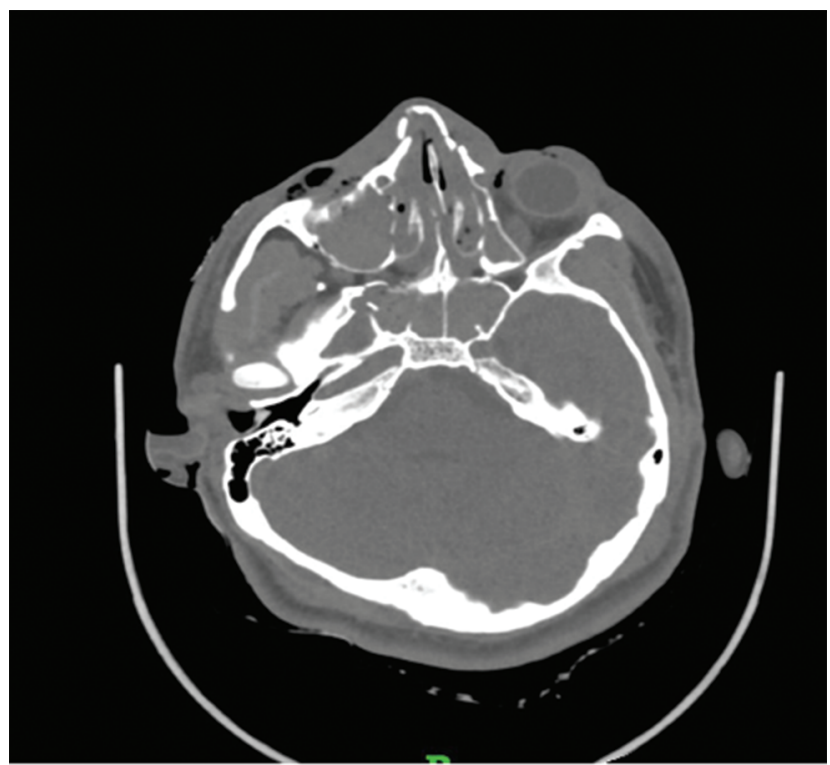

Fig. 2 Plain CT showing right frontal bone fracture and right orbital fracture.

shunt between meningeal branches of external carotid artery (ECA) and CS; type D-B + C (-Fig. 9). CCF usually presents with clinical features of severe ophthalmological and neurological symptoms, ranging from pulsatile exophthalmos, chemosis and subconjunctival hemorrhage, proptosis, progressive visual loss, pulsatile tinnitus, cranial nerve palsy (III, IV, Vc, VI), diplopia, pain and cephalic bruit. ${ }^{4-6}$ The radiological findings in CCF on CT, proptosis, enlarged superior ophthalmic vein, enlarged extraocular muscles, and orbital edema, may show subarachnoid hemorrhage/intracerebral hemorrhage (SAH/ICH) from ruptured cortical veins. ${ }^{7}$ On angiography, rapid shunting from ICA to CS, enlarged draining veins, retrograde flow from CS (most commonly to ophthalmic veins) and US Doppler may show arterialization of ophthalmic veins. ${ }^{7}$

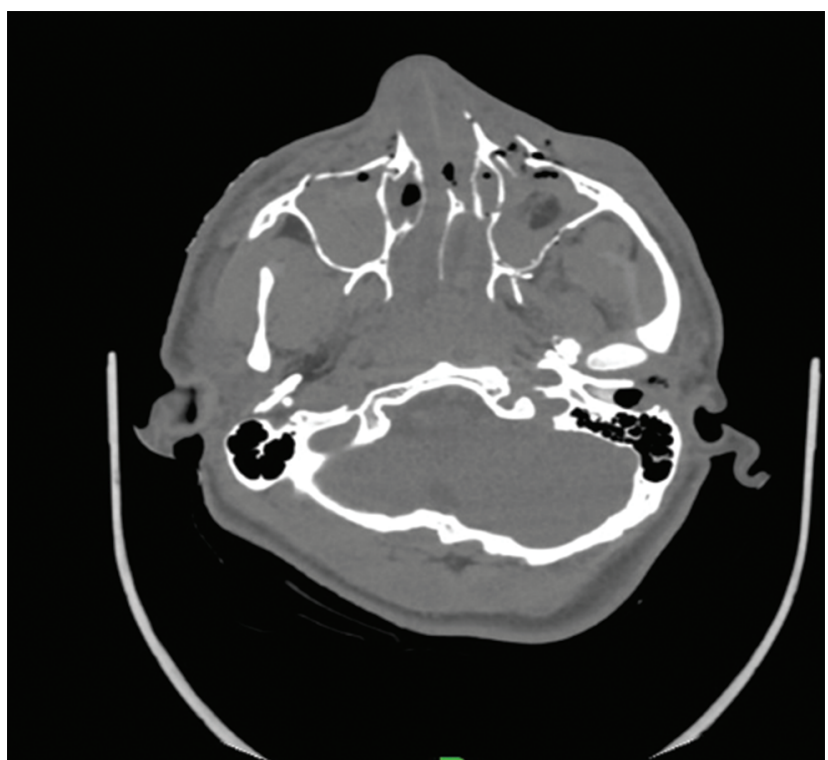

Fig. 3 Bilateral maxillary fracture with hemosinus.

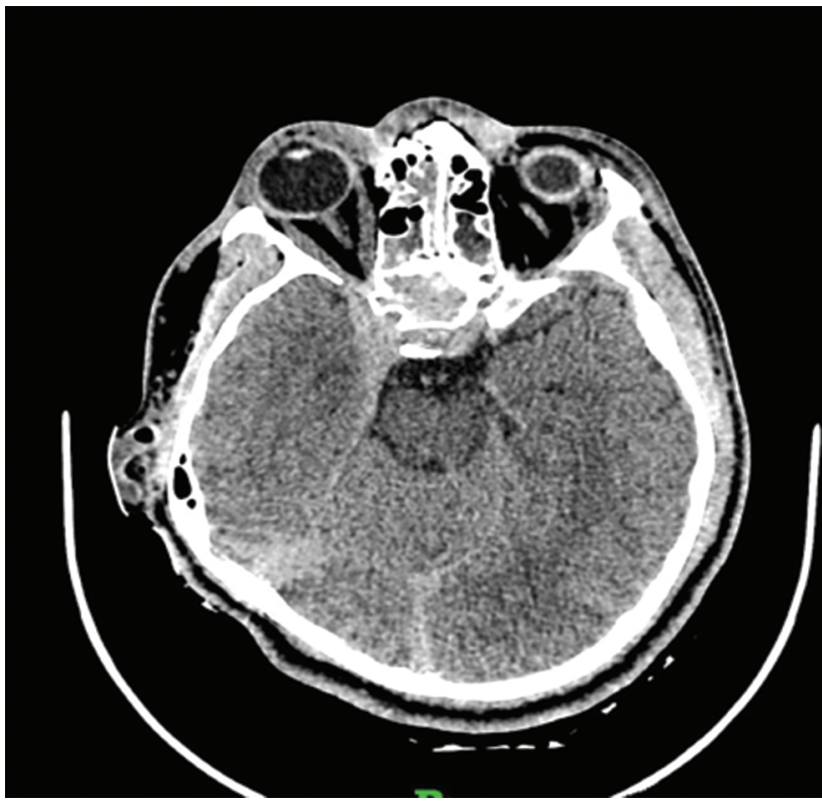

Fig. 4 Resolving left frontotemporoparietal (FTP) subdural hematoma $(\mathrm{SDH})$ with diffuse brain edema.

Goals of treatment in direct CCF are to occlude the tear between ICA and CS, and preserve patency of ICA; for indirect $\mathrm{CCF}$, the goals are to interrupt fistulous communication and reduce CS pressure. ${ }^{8}$ Treatment options include conservative management-manual carotid compression therapy and surgical management including stereotactic radiosurgery and endovascular management. ${ }^{9}$ Endovascular management includes transarterial and transvenous procedures. In transarterial-detachable balloon occlusion, transarterial coil and material embolization, covered stent graft placement: endovascular reconstruction of parent artery and parent artery occlusion can be done. In 


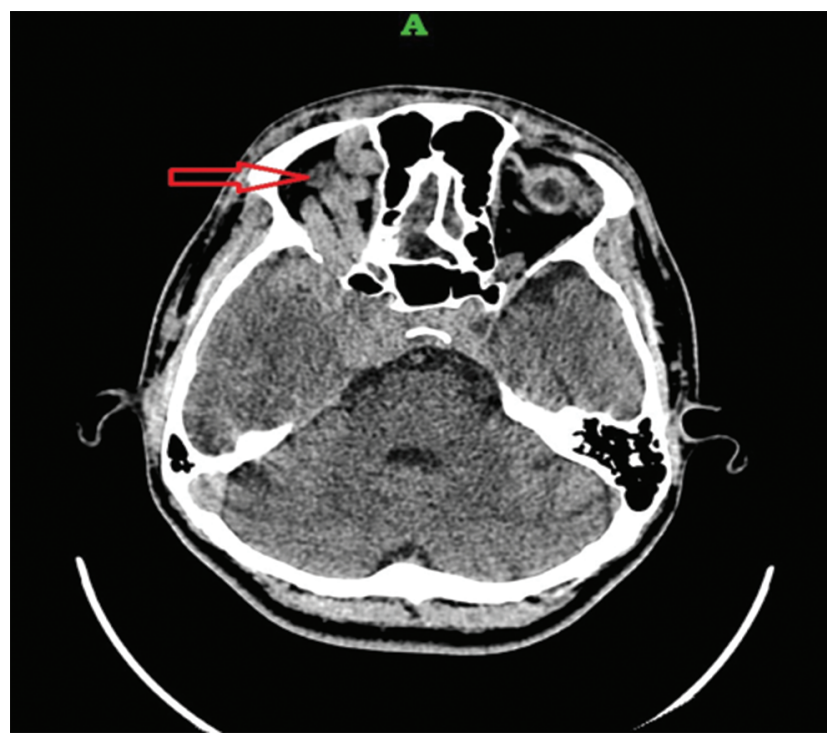

Fig. 5 Dilated and tortuous superior ophthalmic vein.

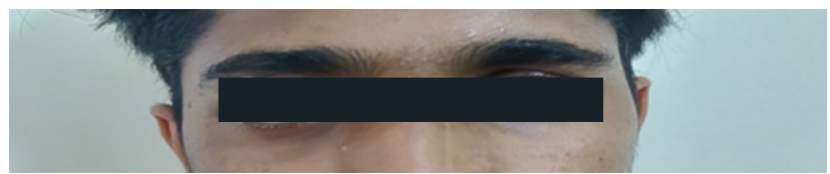

Fig. 6 Exophthalmos present on right side.

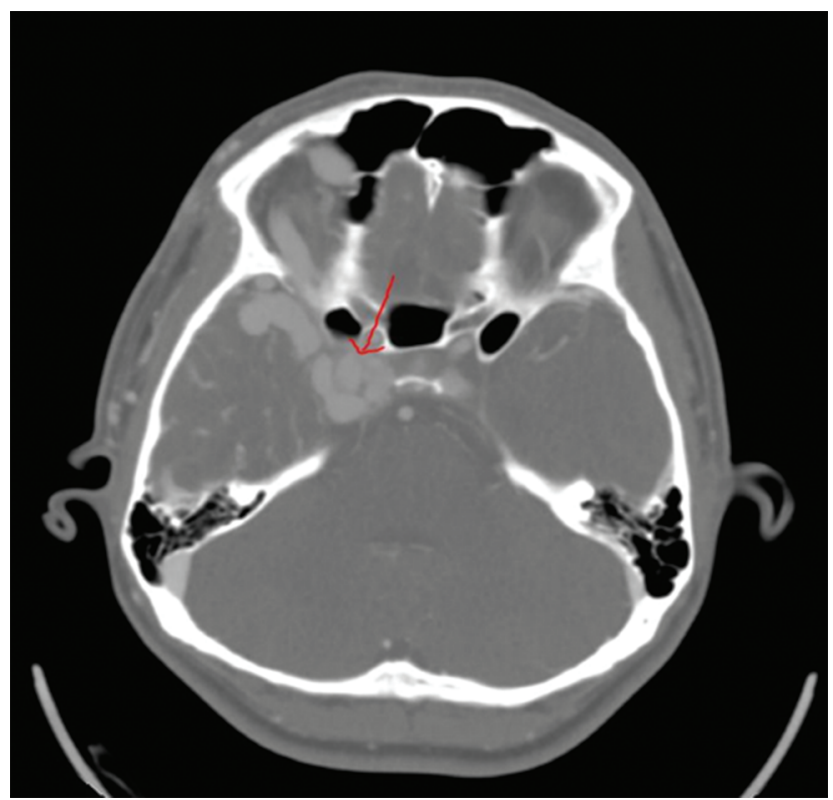

Fig. 7 Fistulous communication between the right intracavernous internal carotid artery (ICA).

transvenous detachable coil embolization, liquid embolizing agents can be used. ${ }^{10}$

\section{Conclusion}

CCF following trauma is a rare finding and it should be considered in differential when patient presents with proptosis following trauma. These patients can be managed with

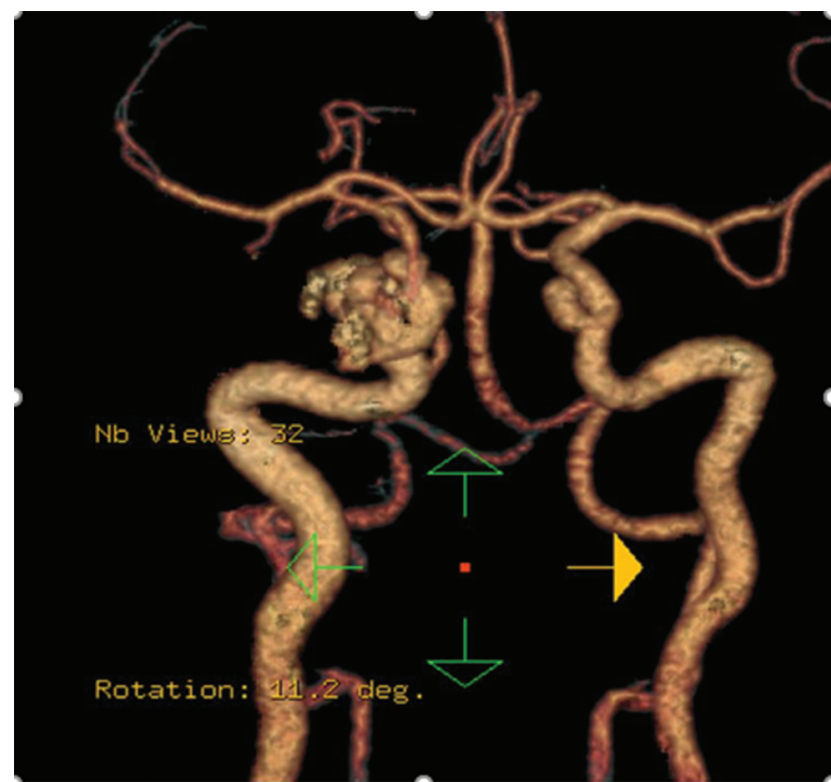

Fig. 8 3D reconstruction image of contrast CT angiogram brain showing right carotid cavernous fistula (CCF).

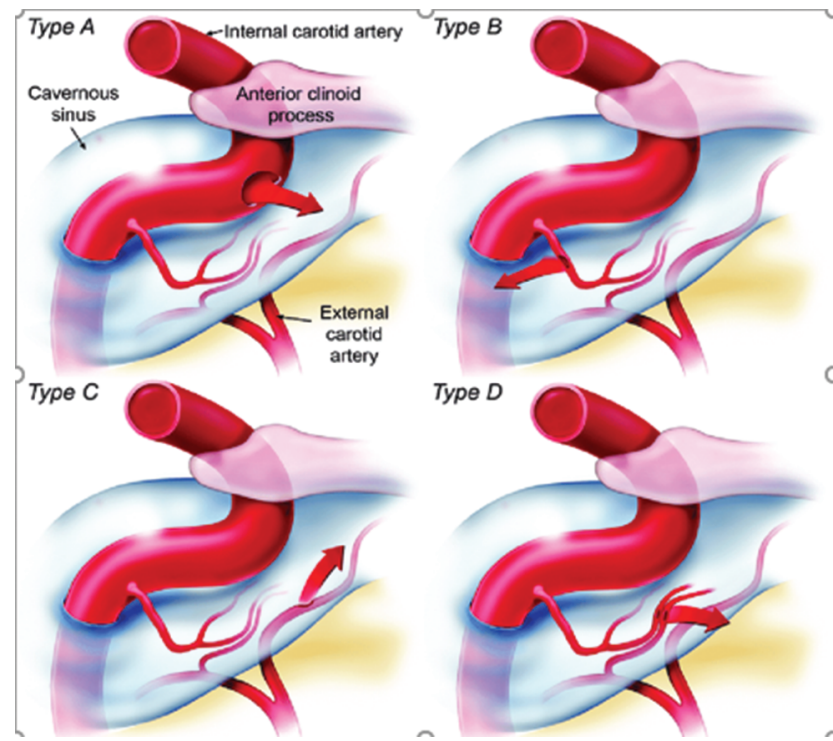

Fig. 9 Classification of carotid cavernous fistula (CCF).

conservative method as well as stereotactic radiosurgery and endovascular procedures. ${ }^{9}$

\section{Conflict of Interest}

None declared.

\section{References}

1 Ringer AJ, Salud L, Tomsick TA. Carotid cavernous fistulas: anatomy, classification, and treatment. Neurosurg Clin $\mathrm{N}$ Am 2005;16(2):279-295, viii

2 Barrow DL, Spector RH, Braun IF, Landman JA, Tindall SC, Tindall GT. Classification and treatment of spontaneous carotid-cavernous sinus fistulas. J Neurosurg 1985;62(2):248-256

3 Ernst RJ, Tomsick TA, Classification and angiography of carotid cavernous fistulas. In: Tomsick TA, ed. Carotid Cavernous 
Sinus Fistula. Cincinnati, OH: Digital Education Publishing; 1997 13-22

4 Beylot C, Bioulac P, Doutre MS. Les manifestations artérielles du syndrome d'Ehlers-Danlos. Ann Med Interne (Paris) 1983;134(5):451-457

5 Weiss DI, Shaffer RN, Nehrenberg TR. Neovascular gluacoma complicating carotid-cavernous fistula. Arch Ophthalmol 1963;69:304-307

6 Grove AS Jr. The dural shunt syndrome. Pathophysiology and clinical course. Ophthalmology 1984;91(1):31-44

7 Keltner JL, Satterfield D, Dublin AB, Lee BC. Dural and carotid cavernous sinus fistulas. Diagnosis, management, and complications. Ophthalmology 1987;94(12):1585-1600
8 Halbach VV, Hieshima GB, Higashida RT, Reicher M. Carotid cavernous fistulae: indications for urgent treatment. AJR Am J Roentgenol 1987;149(3):587-593

9 Tjoumakaris SI, Jabbour PM, Rosenwasser RH. Neuroendovascular management of carotid cavernous fistulae. Neurosurg Clin N Am 2009;20(4):447-452

10 Norman D, Newton TH, Edwards MS, DeCaprio V. Carotid-cavernous fistula: closure with detachable silicone balloons. Radiology 1983;149(1):149-157 